\title{
Privatização, reestruturação e mudanças nas condições de trabalho: o caso do setor de energia elétrica
}

\author{
Rosemeire Aparecida Scopinho ${ }^{1}$
}

\begin{abstract}
O artigo analisa as conseqüências da privatização das empresas geradoras e distribuidoras de energia elétrica para os trabalhadores. Através da realização de observações nos ambientes de trabalho, entrevistas semi-estruturadas e grupos de discussão com os trabalhadores foram identificadas as mudanças introduzidas na base técnica, na divisão e na organização do trabalho e os impactos gerados para a saúde e a segurança dos trabalhadores. Nas empresas de geração de energia, destacam-se o ruído, o trabalho noturno e em turnos e a utilização de produtos químicos nas atividades de manutenção dos equipamentos como as principais cargas geradoras de desgaste. Nas empresas de distribuição de energia, destacam-se o trabalho noturno e em turnos, os movimentos e esforços repetitivos como fontes de desgaste. Em ambos os tipos de empresa, são também expressivas as cargas laborais de natureza psíquica geradas pela intensificação do ritmo das atividades, pela consciência do aumento da insalubridade, periculosidade e penosidade do trabalho e pelo clima de instabilidade organizacional provocado pela privatização. Além de mostrar a precariedade das condições de trabalho, o estudo apontou algumas direções para o aprofundamento da compreensão dos impactos psicossociais da privatização do setor para os trabalhadores.
\end{abstract}

Palavras-chave: organização do trabalho, privatização, saúde e segurança no trabalho

$\mathrm{N}_{\mathrm{i}}$ a década de 1990, o setor elétrico brasileiro passou por grandes mudanças e foi o alvo de inúmeras discussões polêmicas, desde o anúncio e a concretização do processo de privatização das empresas distribuidoras e geradoras de energia, passando pela ameaça e a ocorrência de blecautes de grandes e pequenas proporções, até o advento de uma política de racionamento do uso de energia elétrica em determinadas regiões do país, que ficou popularmente conhecida como "apagão" (Benjamin, 2001; Bernini, 1992; Fischer, Teixeira \& Heber, 1998; Folha de São Paulo, 2001a, 2001b). Este artigo é fruto de uma pesquisa exploratória, realizada conjuntamente com o SINERGIA/PRÓ-CUT, Sindicato dos Energéticos do Estado de São Paulo, e aborda um aspecto da questão que não tem sido debatido pela sociedade mais ampla: os impactos negativos do processo de privatização e reestruturação das empresas geradoras e distribuidoras de energia elétrica para quem trabalha no setor.

Este tipo de trabalho não está a salvo das transformações estruturais que vêm ocorrendo no mundo produtivo (Antunes, 1998; Teixeira \& Oliveira, 1998; Túmolo, 1997; 2001) e nem tampouco das reformas que se processam no Estado brasileiro (Teixeira \& Oliveira, 1998; Pereira, s. d.; Biondi, 1999) e, em decorrência delas, tem assumido características particulares, o que torna o seu estudo necessário e desafiador. No contexto das reformas de inspiração neoliberal, levadas a cabo pelo Estado brasileiro desde meados da

\footnotetext{
${ }^{1}$ Docente do Laboratório de Psicologia Organizacional do Departamento de Psicologia da Universidade Federal de São Carlos (UFSCar). Integrante do Grupo de Trabalho sobre Reestruturação Produtiva do SINERGIA PRÓ-CUT/ Sindicato dos Energéticos do Estado de São Paulo.
} 
década de 1980 e intensificadas na década de 1990, o setor está sendo privatizado² e reestrutura-se, procurando incorporar um conjunto de inovações técnicas e organizacionais para se tornar mais eficiente e competitivo. A reestruturação tem sido sustentada pela necessidade de incrementar a produtividade, de aprimorar a qualidade e de reduzir os custos de produção, para tornar as empresas ainda não privatizadas mais atraentes aos olhos dos investidores. As empresas já privatizadas intensificam o ritmo das mudanças, esforçando-se para tornarem-se ainda mais aptas a enfrentar as regras de uma economia regulada, principalmente, pelo mercado.

No entanto, para os trabalhadores, as inovações tendem a agravar os riscos e intensificar os conflitos existentes no cotidiano da produção. No estado de São Paulo, o que mais gera e consome energia, a privatização tem ocasionado conseqüências sociais negativas, destacando-se, por um lado, o desemprego e, por outro, a intensificação do ritmo das atividades dos que permanecem nas empresas, o aumento da insalubridade, da periculosidade e da penosidade nos ambientes de trabalho, o agravamento da situação de saúde, o aumento da freqüência e da gravidade dos acidentes, entre outras. Para melhor compreender o significado dessas conseqüências, realizou-se um estudo exploratório sobre a organização do processo de produção de energia nas usinas hidroelétricas e do processo de trabalho dos eletricistas da rede de distribuição (eletricista de distribuição), com o objetivo de identificar as mudanças recentes que estão sendo introduzidas na base técnica e na gestão do trabalho, as fontes geradoras de cargas laborais e o padrão de desgaste e de adoecimento manifestado pelos trabalhadores.

Partindo do entendimento de que a saúde-doença é um processo socialmente condicionado e relacionado, sobretudo, ao trabalho e ao conjunto das condições de vida (Laurell \& Noriega, 1989), a análise focaliza a organização do trabalho e a rotina da jornada dos trabalhadores, tendo como pano de fundo a problemática da privatização e da reestruturação produtiva em curso no setor. No que se refere às condições de trabalho, enfoca-se a relação entre objetos de trabalho/matéria-prima, equipamentos e instrumentos de trabalho e os tipos de atividades realizadas, procurando-se caracterizar o ambiente de trabalho, as fontes geradoras e os tipos de cargas laborais e seus impactos para os trabalhadores. Quanto às relações de trabalho, apresentam-se alguns elementos para discutir a política de gestão dos trabalhadores, especialmente no que diz respeito ao treinamento, à organização do trabalho em turnos e à implantação dos programas para obtenção de certificados de qualidade. $\mathrm{O}$ estado de saúde referido pelos trabalhadores e a sua percepção de sinais e de sintomas de doenças foram confrontados com os dados epidemiológicos disponíveis.

Os dados foram obtidos através de análise documental, da realização de observações no ambiente de trabalho, de entrevistas semi-estruturadas e de grupos de discussão com os trabalhadores e sindicalistas (Minayo, 1999; Thiollent, 1997). O campo empírico foi constituído pelos municípios de Ilha Solteira, Porto Primavera, Campinas e Limeira, onde se localizam as mais importantes empresas de geração e distribuição de energia elétrica do estado de São Paulo e do país. O desenho metodológico da pesquisa fundamentou-se, basicamente, nas informações preliminares fornecidas pelos dirigentes sindicais.

\footnotetext{
${ }^{2} \mathrm{O}$ processo de privatização das empresas estatais brasileiras iniciou-se nos anos de 1980, quando o Estado evitou ampliar a sua participação no setor produtivo. Nos anos de 1990, a privatização foi operacionalizada através do Programa Nacional de Desestatização (Lei no 8.031/90), que é apontado como um dos principais instrumentos de reforma do Estado, principalmente a partir de 1995 quando se iniciaram a transferência e a concessão da oferta dos serviços públicos para o setor privado nas áreas de eletricidade, transporte e comunicação. Para entender a história, os objetivos, os principais agentes, os dispositivos legais e órgãos reguladores da privatização das empresas brasileiras, ver Banco Nacional de Desenvolvimento Econômico e Social (s. d.) e Biondi (1999). Para um detalhamento do processo no setor de energia elétrica, ver ainda Folha de São Paulo (1999) e Barbosa (2000).
} 
Nas concessionárias de energia, o posto de trabalho do eletricista de distribuição foi objeto de escolha intencional (Thiollent, 1997) para a realização das observações e para o estabelecimento de contatos preliminares com os trabalhadores. A escolha justifica-se pela importância estratégica que ocupa este posto de trabalho no conjunto das atividades desenvolvidas pelo setor. Além disso, neste posto desenvolve-se atividade de grande risco para o trabalhador e para a população em geral, sendo elevado o número de denúncias que chegavam ao sindicato sobre a ocorrência de acidentes e doenças, mas que nem sempre eram oficialmente notificadas pelas empresas.

Nas usinas hidroelétricas, como não havia indicação de postos de trabalho considerados críticos no que se refere à ocorrência de acidentes e doenças, o processo da pesquisa consistiu na realização de visitas em cada empresa para conhecer o fluxo produtivo da energia, observar o ambiente e a rotina de trabalho de operadores do sistema e trabalhadores das equipes de manutenção, e identificar áreas e elementos de risco.

A partir das observações e contatos preliminares realizados nas usinas e concessionárias, foram organizados grupos de discussão com trabalhadores e sindicalistas na sede das delegacias sindicais. Tais grupos reuniam entre cinco e dez trabalhadores que ocupavam o mesmo posto para discutir a organização do processo de trabalho e todas as informações obtidas passavam pelo crivo do procedimento de validação consensual (Laurell \& Noriega, 1989). As observações e a discussão realizada pelos diferentes grupos de trabalhadores orientaram a elaboração de um roteiro para a realização de entrevistas individuais semi-estruturadas (Minayo, 1988), que, juntamente com a análise documental, foi utilizado para obter informações complementares. Entre os documentos analisados, encontram-se relatórios, boletins, revistas, acordos coletivos de trabalho, pautas de reivindicações e panfletos produzidos pelo sindicato de trabalhadores, pelas empresas e agentes de saúde e segurança no trabalho.

É importante enfatizar que, embora a análise aqui realizada particularize as conseqüências de um determinado modo de organizar e realizar o processo de trabalho para a saúde e a segurança dos trabalhadores, elas somente poderão ser compreendidas tendo como marco referencial a progressiva consolidação do padrão de produção e acumulação capitalista emergente no âmbito mundial a partir dos anos de 1970, cuja essência continua sendo a necessidade de ampliação da taxa de lucro através do desenvolvimento e do acirramento da competitividade empresarial e da intensificação do controle sobre o processo de trabalho.

\section{O trabalho e o ambiente de trabalho dos eletricitários}

Uma usina hidroelétrica é responsável por gerar, transformar e transmitir energia elétrica. O processo de produção da energia é composto, basicamente, por dois tipos distintos de atividades: 1) as de manutenção, que preparam as unidades geradoras de energia (UG) e o conjunto de estruturas e equipamentos para que a produção se realize de modo ótimo e seguro e 2) as de operação, que controlam o funcionamento do sistema e produzem a energia, propriamente dita. Os ambientes onde se desenvolvem essas atividades são caracterizados, principalmente, pela existência de ruído em níveis acima do permitido, vibração e calor constantes (até 43 graus nas proximidades das máquinas) provocados pelo funcionamento ininterrupto das UGs.

As UGs são grandes equipamentos montados dentro da barragem que represa o rio. Estão localizadas num amplo local denominado sala de máquinas e são circundadas por inúmeras galerias que dão acesso ao seu interior, onde se encontra instalado o maquinário das turbinas. A sala onde se localizam os radiadores e trocadores de calor, a casa de máquinas, o 
poço de drenagem, o poço da turbina, o poço da UG e a galeria de filtros são citados pelos trabalhadores como sendo os lugares mais insalubres e perigosos. Há ainda as galerias que se localizam do lado externo da represa, lugares sombrios, úmidos e quentes, onde é comum a presença de animais peçonhentos (cobras, escorpiões e outros), abelhas, morcegos e até mesmo animais que habitam as florestas que margeiam as barragens, tais como gatos selvagens, grandes lagartos, gambás e tamanduás.

A energia de alta tensão produzida pelas UGs passa por transformações de voltagem no local chamado de subestação até ser distribuída para os usuários (residenciais e/ou industriais) através das torres de transmissão e linhas de distribuição. A existência de correntes elétricas de alta tensão e campos eletromagnéticos tornam a subestação um dos locais mais insalubres e perigosos porque é onde os trabalhadores ficam ainda mais expostos aos choques elétricos e à indução.

Nas usinas hidroelétricas, há em curso um processo de digitalização da base técnica, ou seja, a substituição programada dos equipamentos de tecnologia analógica/eletrônica pelos de tecnologia digital utilizados para o controle do processo produtivo. $\mathrm{O}$ posto de trabalho mais ameaçado pela automação é o do operador de UG, porque as leituras dos parâmetros operacionais dos equipamentos podem ser feitas através de tradutores digitais e os dados que informam sobre como eles estão operando podem ser transmitidos para o comando central através de fibras óticas. Os operadores reconheciam que a digitalização representa a obtenção de ganhos de produtividade, porque aumenta o desempenho dos equipamentos e diminui os custos de produção, ao reduzir a necessidade de manutenção. E, ainda, significa praticidade, rapidez e um aumento da segurança do sistema, dado que as informações são obtidas em tempo real.

No entanto, eles também tinham consciência das conseqüências negativas do uso dessa tecnologia porque, por um lado, ela contribui para reduzir postos de trabalho (apenas um homem pode realizar o trabalho de quatro ou cinco), mas, por outro lado, não contribui para qualificar quem as opera. Como ponderou um operador:

É melhor para o sistema, mas para a gente é mais complicado porque dá um defeitinho lá e a gente não tem noção nenhuma [da causa do defeito]. Não dá nem coragem de pôr a mão lá porque ele registra tudo [...] a tendência é reduzir o número de emprego.

A digitalização e o conseqüente desemprego eram vistos pelos operadores como tendências inexoráveis, que se aceleravam com a privatização e o acirramento da concorrência entre as empresas do setor elétrico.

[...] quem não aprender [a operar os equipamentos digitais] vai ficar no meio do caminho, não tem volta. Independente se for trabalhar na usina ou fora, não tem mais jeito. É aproveitar que o barco está andando e remar junto.

No entanto, no interior das usinas hidroelétricas nem toda a tecnologia digital implantada tem sido capaz de contribuir para sanear os ambientes de trabalho, em termos da diminuição dos níveis de ruído, da regulação da temperatura ambiente e da diminuição da vibração. Esses elementos de risco variam de intensidade nos diferentes postos de trabalho, mas estão sempre presentes e atingem indistintamente os trabalhadores, porque são provocadas pelo funcionamento constante das UGs. Não há dispositivos para amenizar os efeitos da vibração e são insuficientes aqueles que regulam a temperatura ambiente. Os protetores auriculares não são utilizados pelos trabalhadores porque são incômodos e ainda dificultam a comunicação por rádio ou telefone, o que é fundamental para garantir a segurança.

Nos postos de trabalho, os operadores realizam a leitura dos equipamentos, 
periodicamente, para verificar a normalidade do funcionamento, colocar/retirar a máquina do sistema, aumentando/diminuindo a sua carga de produção. $\mathrm{O}$ operador somente atua quando há necessidade de desligar um equipamento ou quando uma ocorrência resulta em manutenção na UG, com ou sem parada da produção de energia. Eles explicaram o que significa ser operador de uma usina hidroelétrica:

[...] não é sentar e apertar botão e controlar as máquinas. As máquinas funcionam automaticamente, sozinhas. A gente tem que fazer mesmo é só supervisão.

Essa atividade de controle do processo requer atenção, concentração e o desenvolvimento de habilidades sensoriais importantes como audição, visão, olfato e tato, que auxiliam na detecção de irregularidades e, sem as quais, não é possível trabalhar com segurança. Mas, paradoxalmente, o próprio funcionamento das máquinas provoca uma situação ambiental que prejudica a capacidade sensorial dos trabalhadores, principalmente a auditiva.

Os elementos de risco acentuam-se nas atividades de manutenção corretivas e/ou programadas realizadas no interior das UGs, que podem estar ou não em funcionamento. Ali são manuseados produtos químicos — acetona, benzina, querosene, solventes para limpeza, graxa, óleo, thinner, entre outras - e utilizados inúmeros instrumentais do tipo martelos, alicates hidráulicos e chaves de todos os tipos.

[...o trabalho de manutenção na] subestação é pesado, mas tem a vantagem de ser ao ar livre. Já nas máquinas é um serviço que te deixa em posição muito ruim. Você vai mexer, às vezes, com as bobinas da máquina e tem que mexer com fibra de vidro, calçar [as bobinas] com fibra de vidro, é um lugar muito quente. Acho que ali seria um dos piores na própria manutenção das UGs. Você trabalha dentro dela, é um lugar muito quente, numa posição muito ruim e essa parte que você tem limpar às vezes com thiner, com querosene e ainda tem o problema da fibra de vidro que, na medida em que você bate nela, vêm aqueles farelos em cima da gente.

Os eletricistas de manutenção são subdivididos em equipes, de acordo com as suas especializações em mecânica, elétrica ou eletrônica. Cada equipe tem um líder e pode ter ainda suas subdivisões. Na manutenção não há postos de trabalho fixos, pois as atividades são desenvolvidas em todo o território da usina, desde a fossa séptica até a comporta. Dependendo do problema ou situação, várias equipes de manutenção podem ser acionadas para trabalharem juntas ou isoladas. Isso implica num sério problema de segurança individual e coletiva, pois as atividades devem ser desenvolvidas em sintonia máxima, com atenção redobrada, cada qual conferindo o que o outro faz antes de tomar qualquer decisão em relação à continuidade do trabalho.

Os trabalhadores ressentiam-se do fato de que está diminuindo o número de pessoas nas equipes de manutenção. É que muitos aposentaram-se e a contratação, direta e/ou através de empreiteiras, diminuiu muito depois do início das privatizações. Assim como entre os operadores, entre os trabalhadores da manutenção o clima era apreensivo porque a privatização, associada à digitalização dos equipamentos, ameaçava extinguir os seus postos de trabalho. Essa preocupação era menor nas equipes de manutenção eletrônica, cujos trabalhadores pareciam estar confiantes em que nem mesmo a privatização poderia ameaçar a manutenção dos seus postos de trabalho. Ocorre que a digitalização tende a fazer crescer a demanda de manutenção nos equipamentos eletrônicos, nos sistemas de informática e de telecomunicações.

Porém, o processo de geração de energia digitalizado foge ao controle dos trabalhadores, porque passa a ocorrer através da transmissão eletrônica de dados e informações que não estão disponíveis e acessíveis a todos. Eles ressentiam-se também de 
estarem perdendo o conhecimento e o controle sobre as operações essenciais do processo produtivo e, ainda, preocupavam-se com o fato de que as outras áreas (mecânica e elétrica, por exemplo) estavam perdendo seus postos de trabalho, o que poderia comprometer ainda mais a segurança do conjunto da produção.

Eu acho que é excelente [a tecnologia]. Mas, seria melhor ainda se eles colocassem a gente a par dessa tecnologia. Tem equipamento ali que já faz uns quatro anos que está instalado e a gente não conhece nem 10\%. Enquanto tiver equipamento para substituir eles vão precisar da gente, de nós [...] depois de dois anos de privatizar, depois de tudo isso instalado, aí já não vão mais precisar da gente.

A preocupação explicitada na fala acima é pertinente e mostra que existe uma certa consciência de que os equipamentos não são totalmente digitais, mas, na verdade, constituem um combinado de sistemas mecânicos, elétricos e eletrônicos, cuja manutenção não prescinde dos conhecimentos de outras áreas. Por isso mesmo, eles mencionaram a ocorrência de uma certa resistência entre os trabalhadores da manutenção em adaptarem-se à digitalização, que se manifesta, por exemplo, na recusa da utilização de novos métodos de trabalho.

Entretanto, esta divisão do trabalho entre operação e manutenção está, atualmente, em vias de ser superada. Ocorre que, com a incorporação crescente dos equipamentos de tecnologia digital, há uma tendência para se introduzir nas usinas hidroelétricas o conceito de "homem de produção". Isso significa que o mesmo trabalhador será responsável pelos dois tipos de atividade, ou seja, elimina-se a separação entre manutenção e operação preparando os trabalhadores para o exercício das duas atividades. É que algumas atividades de manutenção tendem a mudar substancialmente, pois, além de o maquinário eletrônico ser mais durável e seguro, a natureza da manutenção é diferente, porque é feita a partir da substituição e não do reparo das peças.

Pode-se considerar que esta é uma mudança estrutural no trabalho desenvolvido nas empresas de geração de energia. A mudança pode até ser positiva, pois o trabalhador, teoricamente, passa a ter um entendimento mais amplo do processo produtivo. Mas, para que isso aconteça, é necessário que ele esteja tecnicamente preparado para compreender as mudanças, porque se trata de uma transformação radical na lógica de funcionamento do sistema de máquinas. É exatamente com relação a esse ponto que os trabalhadores queixavam-se de não estarem sendo informados das mudanças e nem sequer estavam sendo treinados para utilizar os novos equipamentos. E, ainda, lembravam que os postos de trabalho estavam diminuindo e as atividades caracterizando-se pelo exercício da polivalência:

[...] nós fazíamos menos coisas, num tempo maior com o mesmo número de pessoas. Hoje nós fazemos muito mais em menos tempo e com menos pessoas. Manutenção, limpeza e ensaio na proteção demorava de duas a três semanas. Hoje faz em um dia e meio porque não tem mais que desmontar, montar e ajustar mecanismos.

Enquanto nas usinas hidroelétricas os trabalhadores atribuíam as mudanças a uma preparação das empresas para a privatização, nas concessionárias de energia, mesmo depois de privatizadas, as mudanças continuaram acontecendo, especialmente no posto de trabalho do eletricista de distribuição.

O trabalhador deste posto opera em redes de alta tensão (11.900 ou 13.800 volts) que podem estar energizadas (linha viva) ou não (linha morta), realizando os diferentes tipos de atividades de manutenção preventiva e/ou corretiva no sistema elétrico, tendo em vista garantir o fornecimento de energia à população usuária. É um trabalho insalubre, perigoso e penoso, tanto pelas características do objeto sobre o qual ele se aplica quanto porque se realiza na rua, ora em bairros elegantes e diferenciados pela existência de infra-estrutura e de 
urbanismo, ora em bairros periféricos, as fronteiras das cidades marcadas pela existência de favelas caracterizadas pela falta de saneamento básico e, principalmente, de segurança.

No que se refere aos perigos da rua, segundo as estatísticas realizadas por uma concessionária, em 1998, 11,7\% dos acidentes registrados em Comunicação de Acidente de Trabalho (CAT) foram acidentes de trânsito. Além de correr risco de vida, os trabalhadores ainda respondem judicialmente por esses acidentes. Freqüentemente, os denominados eletricistas do comercial — responsáveis pelas atividades de ligação, desligamento e retirada de medidores de consumo das residências — têm que enfrentar a ira do cidadão cuja energia elétrica foi cortada por falta de pagamento. Em certas situações, a segurança e a vida do eletricista depende do seu estado emocional, ou seja, da sua capacidade de dialogar e acalmar os usuários que os ameaçam com cães e até com armas.

[...] nós temos que ir em favelas onde os caras vivem trocando tiros direto, inclusive já houve ocasião de um coitado de um eletricista apanhar de um cara aí. Ameaça a gente tem todo o dia. Por exemplo, você vai trocar uma lâmpada num lugar onde é "boca de fumo", de drogas e para eles não é importante ficar no claro. Geralmente, eles quebram a lâmpada para ficarem à vontade.

[...] eles querem bater na gente e aí você tem que se acalmar. Uma pessoa que não esteja bem de cabeça e espírito vai peitar e é onde vai acontecer o pior. Essas pessoas, normalmente, não estão preocupados com nada. Para eles tanto faz viver ou morrer. Já houve caso de ter que sair correndo. Deram até tiro na caminhonete.

São pessoas frias, elas não medem para fazer qualquer coisa. Você tem que ter bastante equilibrio e pedir muito a Deus para você ir e se sair bem, porque se você for retrucar qualquer coisa vai apanhar ou morrer.

Contudo, apesar dos riscos, havia quem preferisse o trabalho na rua, devido a uma suposta condição de liberdade que ele oferece, mesmo que o controle tenha se intensificado com a privatização:

Eu acho que é mais livre trabalhar na rua, é mais livre. Não tem assim uma chefia imediata pegando no pé. Hoje já tem mais. Do jeito que a coisa está, eles estão mais em cima. Antigamente não, você tinha seu setor, a sua base, eles distribuíam o serviço e você saía para a rua em equipes, por exemplo, em dupla, e lá você era o seu chefe, a sua cabeça era o seu método.

Destaca-se, ainda, que as atividades dos eletricistas de distribuição são realizadas em campo aberto, portanto sujeitas às intempéries e à radiação solar. À noite, as condições de iluminação são precárias e os consertos são feitos à luz de lanternas, aumentando ainda mais a exposição aos riscos de acidentes e assaltos.

Em geral, as operações na rede elétrica são realizadas em alturas de, aproximadamente, oito a dez metros do chão e utilizando-se meios, instrumentos e equipamentos de trabalho especiais. As ferramentas são de inúmeros tipos, desde as menores e mais leves até as mais pesadas e difíceis de manusear, por exemplo, os alicates hidráulicos, que pesam, aproximadamente, cinco quilos e são manuseados - abre/fecha com os braços levantados na altura do tórax - em média, 50 vezes. Esses alicates são apontados pelos trabalhadores como os principais responsáveis por provocar as lesões osteomusculares (LER/DORT), doenças cada vez mais comuns entre os eletricistas. Sobre a oferta de materiais e ferramentas, um eletricista de distribuição comentou:

no começo da privatização foi um tumulto e começou a faltar tudo. Tem muita coisa que antes 
pegava no almoxarifado e hoje a própria equipe quando precisa tem que comprar na praça para poder fazer um serviço bem feito e seguro.

Merecem destaque especial os equipamentos de proteção individual (EPI) utilizados para proteger os trabalhadores das correntes energizadas, entre os quais se destacam as luvas de algodão, de borracha e de raspa de couro (vestidas nesta ordem e em sobreposição) e os mangotes de borracha ${ }^{3}$. Em uma empresa, os mangotes, antes importados, estavam sendo substituídos pelos de fabricação nacional. Segundo os trabalhadores, o custo é de, aproximadamente, $55 \%$ mais baixo, mas, em compensação, o EPI é mais pesado e menos flexível, o que dificulta os movimentos do corpo e intensifica o esforço repetitivo no manuseio das ferramentas. Parece evidente que o esforço empresarial para baratear os custos de produção utilizando equipamentos e materiais de pior qualidade está trazendo conseqüências diretas para a saúde dos trabalhadores. É necessário realizar estudos específicos para melhor esclarecer a relação entre a piora da qualidade dos EPIs e o aumento de queixas de LER/DORT.

Destaca-se também que se, por um lado, é certo que esses EPIs são indispensáveis para a realização do trabalho com segurança, por outro lado, é unânime entre os entrevistados a opinião de que o seu uso, associado à exposição ao sol, causa um desconforto térmico muito grande. A transpiração excessiva pode provocar a perda de sais minerais importantes para o bom funcionamento do organismo, o que pode levar o eletricista a sentir caimbras, dores musculares e tonturas e provocar acidentes fatais, porque o trabalho é realizado em alturas elevadas e operando linhas energizadas.

O eletricista de distribuição realiza um conjunto de diferentes operações como a expansão de linhas, a colocação e a troca de postes, os consertos, as trocas e as regulagens em geral, a ligação/desligamento de energia nos prédios, a colocação e a retirada de medidores de energia, entre outras. Os plantonistas realizam consertos e manutenção na rede em situações de emergência. Essas atividades são desenvolvidas, geralmente, por equipes compostas por dois ou três trabalhadores. Os trabalhadores explicaram que equipes maiores ou menores podem tornar o trabalho ainda mais perigoso. Quando as equipes são maiores, alguém pode ficar ocioso e distrair-se, e pode provocar acidentes; quando elas são menores, intensifica-se o ritmo do trabalho, e isso pode determinar supressões de etapas importantes dos procedimentos de preparação do campo e de manuseio da rede energizada.

A organização do trabalho em equipes é um fator de agregação, de solidariedade e de estabelecimento de vínculos entre as duplas. A cooperação, o sentimento de pertencimento, a noção de trabalho coletivo são importantes para a segurança desses trabalhadores, porque a atividade requer das duplas e das equipes uma grande sincronia na execução dos movimentos e passos. Cada operação é uma seqüência de atividades logicamente articuladas, que deve ser segura e firmemente incorporada porque disso depende a própria segurança de cada trabalhador, a dos outros companheiros de equipe e a de todos os usuários da rede de energia elétrica. Para garantir um mínimo de segurança, a realização das atividades requer conhecimento técnico, treinamento de habilidades, capacidade de obediência rigorosa aos passos de uma determinada seqüência de tarefas, capacidade de concentração e de trabalhar em equipe, de sintonizar-se com os companheiros no processo de tomada de decisão, nas atitudes e nos comportamentos relativos ao trabalho.

O trabalho de cada um, em geral, exige uma seqüência de movimentos repetitivos, finos ou não, que ocupam todo o corpo do trabalhador, sobretudo os membros superiores. A

\footnotetext{
${ }^{3}$ Espécie de mangas (de camisa) de borracha flexível que são vestidas sobre a roupa e presas uma na outra na altura dos ombros, que servem para isolar os braços das correntes elétricas.
} 
primeira seqüência de procedimentos é a de reconhecer a área, avaliar as condições de realização do serviço, preparar e sinalizar o local com os cones e as fitas de isolamento fosforescentes.

A segunda seqüência diz respeito à preparação dos trabalhadores, que vestem e ajustam seus EPIs, apanham as ferramentas que deverão utilizar na operação colocando-as ao seu alcance. Esse é um ritual que deve ser feito passo a passo, com atenção para não haver esquecimento ou falha na preparação. A comunicação entre os trabalhadores é feita também através de olhares, ritmos e movimentos sincronizados.

A terceira seqüência refere-se à preparação do campo de trabalho, propriamente dito. É a seqüência mais importante porque diz respeito ao isolamento das correntes de modo a evitar a formação dos campos energizados denominados de arcos (regiões delimitadas entre os fios de alta tensão), onde a temperatura elevada pode provocar graves queimaduras ou mesmo levar à morte instantânea, dependendo do tipo da corrente, das condiçóes do ambiente que favorecem a condução da energia (chuva, por exemplo) e também das condições do próprio organismo do trabalhador. Um dos eletricistas opera enquanto o outro acompanha atentamente a seqüência de procedimentos realizada e auxilia fornecendo material, equipamentos, comunicando-se com o terceiro que está no chão. Este, por sua vez, monitora o trabalho dos que estão em cima, sempre atento às necessidades de material e de equipamentos de segurança e, ainda, monitora as condições do tráfego na rua, o trânsito de veículos e de pedestres.

A ajuda do companheiro é importante para alertar sobre os passos esquecidos na realização da tarefa. A atenção e a concentração requeridas para executar as operações são, ao mesmo tempo, focalizadas e difusas. Ao mesmo tempo em que os eletricistas visualizam e atentam para um determinado ponto da linha de transmissão de energia que está sendo alvo de manutenção, reparo ou qualquer outro procedimento, eles também devem vigiar um raio mais restrito onde se encontra a rede de fios, olhando para os lados, para cima e para baixo, para dentro da caçamba do guindaste que os eleva na altura certa dos postes, o companheiro na outra caçamba. Em um raio mais amplo, vigiam o caminhão, as ferramentas e os materiais para não serem vítimas de furto e, ainda, vigiam a rua, o trânsito, os transeuntes, as árvores, o tempo anunciando a possibilidade de chuva.

É consenso entre os trabalhadores que, quando um eletricista trabalha sozinho, aumenta a probabilidade de ocorrência de acidentes. Alguns afirmaram que o hábito de beber e fumar pode prejudicar a atividade, porque ocorre a perda da capacidade de concentração e do equilíbrio emocional.

Apesar da periculosidade, ser eletricista de linha viva é o desejo de muitos, porque o salário é maior e o trabalho não é realizado em dias de chuva, à noite ou em escala de revezamento. As equipes revezam-se nas tarefas todos os meses realizando operações na linha viva, plantão e manutenção. Por um lado, uma certa rotação nas atividades é importante para esses trabalhadores, pois permite que eles mantenham a noção da totalidade do sistema de energia elétrica. Mas muitos se queixaram de que, em cada mudança, leva-se um tempo de readaptação da seqüência de procedimentos da tarefa e corre-se um risco maior de sofrer acidentes por esquecimento.

A polivalência era percebida, ainda, em relação a uma mesma atividade quando, por exemplo, além de eletricista, o trabalhador poderia ser também o motorista do veículo utilizado para o transporte da equipe. Os trabalhadores explicaram:

Hoje na empresa a filosofia é uma só: é você não ter, por exemplo, uma especialidade. Você tem que fazer tudo: iluminação, corte, instalação de medidor, nós fazemos tudo também.

Eles consideravam que o trabalho é penoso, no sentido atribuído por Sato (1993), ou 
seja, porque não é possível controlar todas as condições e cargas nele presentes, e que o surgimento de doenças como estresse, dores e insônia está relacionado à polivalência.

\section{A gestão do trabalho e dos trabalhadores}

Quanto à gestão do trabalho e dos trabalhadores, é importante considerar, principalmente, três questões: o treinamento, a implantação dos programas para obtenção de certificados de qualidade e a realização do trabalho em turnos e noturno.

Dada a natureza perigosa das atividades, o treinamento adequado para a execução das tarefas é sinônimo de segurança para os trabalhadores, para as instalações e para a população em geral. Isso leva as empresas a investirem em programas de treinamento, mas, segundo os eletricistas, os investimentos já não são tão expressivos e constantes depois da privatização, porque apenas os novatos estão sendo treinados.

É consenso que a principal ferramenta de trabalho do eletricista é a sua própria experiência, que inclui tanto a aquisição de um amplo repertório de conhecimentos técnicos especializados quanto os chamados "macetes de ofício" (Dejours, Abdoucheli \& Jayet, 1994). Essa experiência é construída cotidianamente, através da efetiva realização do trabalho e da convivência com os companheiros, e permite detectar as causas dos defeitos na rede com mais agilidade e precisão, e executar o trabalho da maneira mais segura. Tanto isso é verdade que, segundo os entrevistados, a ocorrência de acidentes é maior entre os trabalhadores mais jovens e com menos tempo de trabalho.

A importância do treinamento formal e teórico é amplamente reconhecida, mas é opinião unânime entre os entrevistados que um eletricista de distribuição está formado para trabalhar na linha viva com eficiência e segurança, depois de, pelo menos, cinco anos de trabalho contínuo.

Aprende-se mais no dia-a-dia, na prática, mas também é necessário o conhecimento teórico, porque você tem que saber o que você tem na mão... a diferença entre um potencial [de energia] e outro.

A relação entre treinamento adequado e segurança, individual e coletiva, sempre está presente nos depoimentos:

[...] porque é para você fazer um trabalho com responsabilidade, é para você saber o que está fazendo, entendeu? Eu acho que você tem que saber o que está empregado na rede, a maneira como você vai trabalhar com os equipamentos que você tem na mão para a garantia daquele serviço. Eu acho necessário o treinamento, eu acho importantíssimo para tudo, para consertar um determinado fio em tal cabo da rede, porque não é só chegar e tal e enrolar o cabo e ir embora. Se você não conhecer você acaba pondo em risco a sua vida e a vida dos outros.

Muitos referiram que os primeiros anos de trabalho são muito difíceis porque, além de tudo, é necessário aprender a lidar com os riscos e, ainda, adaptar-se ao trabalho, que é feito em cima de escadas, preso ao cinto de segurança e vestido com os EPIs.

No que se refere aos treinamentos, a realidade observada nas usinas hidroelétricas é um pouco diferente. Nestas empresas eles foram intensificados, mas o fato está diretamente relacionado à implantação dos programas que visam a obtenção dos certificados de qualidade conferidos pela ISO (International Standart Corporation). Assim como os trabalhadores das equipes de manutenção, os operadores das usinas hidroelétricas precisam de tempo para se formarem, ou seja, através da prática orientada desenvolver um conjunto de habilidades e atitudes que compõem os diferentes perfis requeridos pela atividade. A diferença entre o perfil do operador de UG e do trabalhador da equipe de manutenção é que o primeiro tem que ser ágil e rápido na intervenção para resolver os problemas e, conseqüentemente, evitar 
as paradas dos equipamentos; o segundo deve ter, principalmente, capacidade de análise e diagnóstico das circunstâncias em que ocorreu o defeito no equipamento, para poder atuar diretamente na parte avariada sem prejuízo das demais e sem a interrupção da produção de energia.

Os trabalhadores da manutenção chamaram a atenção para o fato de que os novos equipamentos estavam sendo introduzidos sem que houvesse treinamento específico para operá-los. Segundo eles, esses equipamentos raramente apresentam defeitos e, quando acontecem, o conserto não é de reparo, mas de substituição da peça ou de partes dela. Os treinamentos formais eram cada vez mais raros, e eles confessaram que também não conseguiam se organizar entre si para trocar informações essenciais, ou porque a empresa é muito burocrática e rígida nas suas normas de treinamento, ou porque falta capacidade de mobilização e organização entre ou próprios trabalhadores:

\section{[...] os equipamentos novos são dois ou três que dominam. O resto, ninguém sabe ainda como é} quéé.

Dada a importância dos treinamentos para a realização segura das atividades no setor elétrico, essa questão merece um estudo aprofundado porque, sem dúvida, a formação do trabalhador é um dos componentes essenciais de uma cultura organizacional realmente preventiva no que se refere à saúde e segurança. Do ponto de vista das empresas, a introdução de novas tecnologias, seja na base técnica (materiais e/ou instrumental de trabalho) seja na gestão organizacional e do trabalho (Programas de Qualidade Total e outros métodos de gestão etc.), está estreitamente associada à questão da qualificação/adaptação dos trabalhadores ao processo produtivo "modernizado", ou seja, importa a construção de um determinado perfil de trabalhador que maximize os investimentos feitos. Do ponto de vista dos trabalhadores e da população usuária da rede de energia elétrica, o fundamental é desenvolver a capacidade de atendimento das demandas com segurança máxima.

Quanto à implantação das normas para a obtenção do certificado ISO 9002 nas usinas hidroelétricas, parece que houve participação ativa dos operadores. Se não fosse assim, eles não teriam conseguido acompanhar as novas rotinas de trabalho implantadas, o que tornaria a atividade ainda mais perigosa. Para os trabalhadores da manutenção, a obtenção da certificação não alterou substancialmente a rotina do trabalho, porque todos os procedimentos já eram regidos por normas: "[...] é um dos itens da norma: faz o que está escrito e escreve o que faz". Algumas mudanças positivas foram apontadas, por exemplo, a melhoria dos serviços de rotina porque os equipamentos foram identificados, alguns documentos tornaram-se mais acessíveis e podem ser mais facilmente localizados. Em compensação, o trabalho ficou mais burocrático, não há espaço para o trabalho não-prescrito e alguns procedimentos importantes para a segurança não são mais realizados. Apesar das mudanças positivas ocorridas nos últimos anos na política de gestão de recursos humanos de uma concessionária, que passam pela eliminação do cartão de ponto e por um tratamento considerado mais humanista, os trabalhadores queixavam-se de que faltavam mecanismos de valorização e de incentivo, por exemplo, um plano de carreira.

Em suma, nas usinas hidroelétricas estudadas, grande parte dos trabalhadores entrevistados entendia que a certificação ISO é um procedimento "para inglês ver", isto é, uma forma de intensificar o ritmo do trabalho e, mais do que uma preocupação com a segurança e a qualidade do processo, é um modo de apropriação do conhecimento acumulado pelos trabalhadores porque

[...] quando privatizar eles já sabem o procedimento e qualquer um que não tem qualificação pode fazer [o trabalho].

A intensificação do ritmo do trabalho evidencia-se quando se analisa o que ocorre 
com as jornadas. Merece destaque o plantão realizado nas empresas de distribuição, cujo problema está relacionado com as escalas de revezamento que incluem o trabalho nas madrugadas. As opiniões dos trabalhadores sobre o assunto estavam divididas: alguns contra, porque não se acostumavam ao trabalho noturno; outros a favor, alegando que são apenas duas madrugadas de trabalho compensadas pela possibilidade de ter, praticamente, quatro dias de folga. Considero importante aprofundar a investigação sobre como o trabalhador aproveita as suas folgas, pois parece que muitos deles podem estar utilizando o tempo livre para fazer trabalhos extras, como forma de complementar o salário. A natureza exploratória desta pesquisa não possibilitou um aprofundamento desta questão, o que deve ser feito em uma próxima etapa do estudo, no contexto da análise das condições e estratégias de reprodução das famílias dos eletricitários.

Mas, se o plantão podia ser considerado um "serviço mais leve", porque as atividades eram feitas com a rede desligada, em compensação, ele estava sendo descaracterizado enquanto o trabalho de uma equipe que permanece de prontidão para o atendimento de emergências, porque as duplas estavam sendo designadas para realizar outros serviços, enquanto esperavam os chamados. Os trabalhadores eram requisitados, principalmente, para fazer serviços de manutenção da iluminação pública, ou seja, a troca de lâmpadas queimadas nos postes de rua, nas praças etc., porque durante a madrugada o trânsito de veículos é menos intenso.

O trânsito pode ser até mais tranqüilo, mas é muito mais perigoso trabalhar nas ruas neste horário porque é maior a probabilidade da ocorrência de assaltos e outras formas de violência. Esta é uma medida de racionalização do trabalho das equipes que intensifica muito mais o ritmo e provoca um desgaste adicional nos trabalhadores, além de todos os transtornos orgânicos e psicológicos que o trabalho organizado em turnos e noturno pode acarretar. Os plantonistas alegaram que, para realizar o trabalho nos plantões, a equipe deve estar descansada e preparada, tanto física quanto emocionalmente. $O$ argumento é válido porque as emergências são situações, por natureza, totalmente imprevisíveis e, às vezes, arriscadas, que expõem ainda mais os trabalhadores e a população aos perigos da atividade.

Além do trabalho em turnos e noturno, há também a situação de sobreaviso, ou seja, em finais de semana alternados os eletricistas estão de folga, mas devem estar de prontidão para atender os chamados de emergência, não podendo realizar passeios em locais muito distantes da central e/ou viagens e nem ingerir bebidas alcoólicas, por exemplo. Este é o chamado "sobreaviso moral", porque o trabalhador está de folga, mas, ao mesmo tempo, está à disposição da empresa e não recebe nenhuma remuneração por isso.

Os temporais são motivos de grande preocupação. Quando eles ocorrem, as equipes de eletricistas de distribuição estão sempre sujeitas ao aviso permanência no posto de trabalho, até segunda ordem. É que, quando o tempo anuncia chuva pesada, as turmas que estão terminando a jornada não são dispensadas até que as primeiras chamadas da população aconteçam. Os trabalhadores entendem que a necessidade de estar alerta 24 horas por dia, a dedicação quase integral que a atividade exige não pode ser compensada com o aumento de salário. Eles referiram o fato de "estar preso" ou "amarrado", porque, quando não estão trabalhando, têm que descansar para poder executar o trabalho com segurança.

A consciência de que o trabalho é perigoso é um importante fator de sobrevivência para esses trabalhadores, mas, ao mesmo tempo, gera preocupação, desgaste e sofrimento psíquico. Ocorrem mudanças na rotina, na vida social e no organismo, que geram uma necessidade constante de adaptação. Essa é justamente a questão fundamental que está colocada no conceito de desgaste proposto por Laurell e Noriega (1989): o esforço permanente de adaptação a situações novas, que pode gerar adoecimento e morte precoce. 


\section{A privatização e o desgaste dos trabalhadores}

Mesmo tendo sido de natureza qualitativa e exploratória, o estudo permitiu identificar as cargas de trabalho existentes no processo de geração de energia e no processo de trabalho dos eletricistas de distribuição. Pode-se afirmar que o perfil de adoecimento dos trabalhadores possui especificidades relacionadas ao modo de organizar e realizar o trabalho.

Entre os operadores, as principais queixas relacionadas à saúde eram de nervosismo e de insônia, provocadas pela tensão gerada no trabalho.

Esse operador aqui, por exemplo, uma falha dele pode provocar um blecaute no Brasil. Mas, ele não tem esse valor, a empresa não dá esse valor.

Um blecaute é sempre uma situação inédita e assustadora pela emergência, complexidade e responsabilidade social que representa.

De repente você vê na televisão blecaute não sei onde por falha humana. Todos nós somos humanos e podemos errar, só não podemos errar ali dentro, deixar aí meio mundo no escuro por causa de uma falha.

Cada uma das irregularidades ocorridas na rotina da jornada de trabalho deve ser objeto de justificativa e de explicação detalhada das suas causas. Quando o relatório aponta que se trata de falha humana, o clima de tensão na equipe se acentua, pois as atenções voltam-se para o responsável. Parece que, para esses homens, ser infalível, além de ser uma questão de segurança, é também uma questão de honra. Percebeu-se que os trabalhadores, principalmente os mais antigos, foram especialmente formados para trabalhar de tal modo e levados a introjetar uma noção de responsabilidade que hoje já não se aplica nas situações de trabalho, devido às mudanças ocorridas na base técnica e na gestão empresarial. Quer dizer, atualmente, já não há mais condições objetivas para desenvolver a atividade conforme as instruções recebidas em treinamento e a experiência adquirida ao longo dos anos de trabalho, mas a responsabilidade pelos eventos imprevistos e sinistros continua sendo, geralmente, atribuída aos trabalhadores. Essa é, sem dúvida, uma das mais importantes fontes de sofrimento psíquico para os eletricitários.

Mas o alívio dessa tensão permanente nem sempre é conseguido através de alternativas saudáveis. A pescaria, os desabafos com os amigos e com a esposa, a cachaça, os jogos de computador, a internet e a prática da fofoca (entre os trabalhadores de uma mesma equipe) foram opções de lazer e de relaxamento mais citadas.

Nas equipes de manutenção, além das cargas psíquicas, os trabalhadores estavam expostos, principalmente, às cargas de natureza física, química, fisiológicas e mecânicas. Entre as principais causas de acidentes referidas estavam as quedas que provocam cortes e entorses. As principais doenças referidas foram hipertensão, estresse, LER/DORT, problemas respiratórios provocados pelos choques térmicos, dormências e dores nas pernas provocadas pela vibração, problemas gástricos, dores de cabeça e nas articulações, lombalgias, gota, dores no fundo do olho, "friagem", tensão nervosa, hipocondria, ansiedade generalizada, entre outros.

Nas concessionárias, o ritmo de trabalho intensificado nos últimos tempos, além de provocar um aumento das queixas de LER/DORT, também aumentou o número de queixas relacionadas ao estresse e à fadiga crônica. As manifestações das cargas do tipo psíquico traduziram-se em queixas de problemas gastrointestinais, transtornos do apetite e do sono, ansiedade, problemas de adaptação social e familiar, que podem estar estreitamente associados à realização do trabalho noturno e em turnos, à consciência da periculosidade, ao medo do desemprego que a privatização pode gerar. Nessas condições, dificilmente o trabalhador terá a condição emocional necessária para enfrentar as situações perigosas que 
podem ocorrer, por exemplo, durante os atendimentos de emergência ou no trato com os usuários enfurecidos pela possibilidade de corte de fornecimento de energia. Por exemplo, eles alegaram que as esposas e os filhos reclamam das ausências provocadas pela realização do trabalho noturno e nos finais de semana, da queda brusca no padrão de vida que levou as famílias a mudarem para as periferias das cidades, entre outras questões. Esse é mais um indicador da importância de aprofundar a investigação sobre as condições de reprodução social dessas famílias.

Quem trabalhava na linha viva queixava-se do mal-estar provocado pelo excesso de transpiração. Queixava também de dores nos ombros e braços. Para uns, as dores eram causadas pelas mudanças bruscas de temperatura, ou seja, as "friagens" recebidas ao retirar os EPIs do corpo, que fica exposto às correntes de ar com a roupa molhada de suor; outros as atribuíam aos tipos de EPIs associados ao uso de ferramentas pesadas. Não foi possível obter dados sobre a incidência de casos de LER/DORT, mas as queixas eram muito freqüentes e, provavelmente, devidas ao uso de ferramentas, instrumentos e EPIs inadequados (e não ao uso inadequado de ferramentas, instrumentos e EPIs como alegam as empresas). Acrescentese ainda o prolongamento das jornadas, a intensificação do ritmo do trabalho, entre outras características do modo de organizar e realizar o trabalho no setor, que também contribuem para aumentar a incidência desse tipo de doença. Melhorar as condições de oferta dos EPIs, certamente, não garantiria a saúde e a segurança desses trabalhadores, mas poderia significar um certo avanço na prevenção dessas doenças. Ao se cronificarem, as LER/DORT incapacitam as pessoas para quase todos os tipos de trabalho, especialmente os eletricitários, cuja atividade não prescinde do uso adequado do corpo, principalmente os membros inferiores e superiores.

Em uma das usinas, a elaboração do mapa de risco (previsto na Norma Regulamentadora no 9) foi um processo participativo, que demorou mais de um ano e foi feito por uma comissão formada por engenheiro de segurança e técnicos de diferentes áreas. Observei que as reuniões que tratavam de assuntos relacionados à saúde e à segurança são freqüentes e envolvem mais de 100 trabalhadores. No entanto, elas não passavam da realização de palestras sobre temas variados, desde os que diziam respeito à saúde (obesidade, hipertensão, entre outros) até motivação para o trabalho, relações interpessoais etc.

Para os trabalhadores entrevistados, se, por um lado, a Comissão Interna de Prevenção de Acidentes (CIPA) é atuante, por outro, o seu funcionamento é burocrático, devido à rigidez hierárquica característica dessas empresas. Um importante problema apontado foi a falta de comunicação entre essas formas de organização no local de trabalho e os trabalhadores, refletida nas dificuldades de socializar o conhecimento sobre as inovações que estão sendo introduzidas no processo produtivo, sobre segurança e prevenção de acidentes e até sobre o uso dos benefícios assistenciais oferecidos pelas empresas, principalmente os relacionados à aposentadoria. A preocupação com a aposentadoria era muito evidente e poderia estar relacionada com a iminência das privatizações, quando as demissões voluntárias e/ou aposentadorias, em alguns casos, apareciam como alternativas.

Quanto aos acidentes, segundo os entrevistados, o número aumenta quando um eletricista deixa de trabalhar na linha viva e passa para a linha morta. Isso porque, na linha viva, o eletricista é especialmente treinado para lidar com o perigo, sendo fundamental que adquira autoconfiança. No entanto, às vezes, os acidentes acontecem justamente por excesso de autoconfiança; outras vezes, eles acontecem porque o trabalhador dispensa os procedimentos básicos de segurança pelo fato de estar trabalhando na linha morta. Segundo o boletim de informe mensal sobre a ocorrência de acidentes do trabalho produzido por uma concessionária, o eletricista de distribuição é o trabalhador que mais se acidenta no setor, com ou sem afastamento do trabalho. Do total de 120 acidentes registrados em 1998, 75 $(62,5 \%)$ não resultaram em afastamento do trabalho, 14 (11,7\%) foram de trajeto e 106 $(88,3 \%)$ foram acidentes típicos. O tipo de acidente sem afastamento predominante é o 
ataque de ser vivo (abelhas, cães, animais peçonhentos), que representou 33\%, seguido dos do tipo impacto sofrido $(23,2 \%)$. Os acidentes com afastamento representaram $37,5 \%$ do total, e os tipos predominantes foram impacto contra $(13,3 \%)$, queda com diferença de nível e origem elétrica $(11,1 \%)$, entre outros significativos.

No mesmo ano, o número de acidentes ocorridos com os trabalhadores contratados pelas empreiteiras foi maior do que o número de acidentes que envolveram os diretamente contratados, mas não foi possível ter acesso ao número total de empregados contratados, direta e indiretamente, para analisar o significado desses dados. Dos 204 acidentes ocorridos com os trabalhadores indiretamente contratados, 93,6\% referiam-se à área de distribuição e operação, e apenas $6,4 \%$ à área administrativa e financeira.

Com relação às empreiteiras, os eletricistas comentaram simplesmente que "...a maneira de trabalhar não coincide com a nossa". Isso quer dizer que, para os eletricistas, a subcontratação significa re-trabalho e aumento do risco de acidentes porque, geralmente, os trabalhadores contratados pelas empreiteiras não estão qualificados para o exercício das atividades. No entanto, os entrevistados reconheciam que a situação já havia sido muito pior, pois estava em curso um certo processo de adaptação. Os depoimentos coletados junto ao departamento jurídico do SINERGIA revelaram que os trabalhadores contratados pelas empreiteiras demandavam muitas ações trabalhistas contra as empresas, principalmente para requerer enquadramento de função, ressarcimento de gastos com treinamento, denunciar excesso de horas na jornada e não-pagamento de horas extras.

Apesar das muitas especificidades que podem ser apontadas quanto ao trabalho e à situação dos trabalhadores das usinas hidroelétricas e das concessionárias de energia, há uma questão que é comum para ambos: o medo em relação aos perigos da atividade e à privatização do setor. Aparentemente, as opiniões sobre os riscos estavam divididas e muito revelavam sobre os mecanismos de defesa psicológica que são desenvolvidos para enfrentar e conviver com os perigos.

A responsabilidade e a pressão sobre esses trabalhadores são de tal ordem que se desenvolve, principalmente, uma espécie de compulsão para repetir procedimentos de verificação para evitar o risco de esquecimento daqueles que comprometem a segurança. Desenvolve-se também um sentimento persecutório, pois é importante acreditar que os perigos estão em todos os lugares e em todos os momentos. Ou uma negação total da existência dos riscos, uma prepotência e uma certeza cega de que o perigo nunca irá ameaçálos. Se, por um lado, esses são sentimentos e comportamentos importantes para garantir a sobrevivência dos trabalhadores nas situações de trabalho, por outro lado, o mesmo não pode ser dito quanto aos outros aspectos da vida por onde eles se estendem interferindo nas relações pessoais. Todos concordaram que a comunicação entre os membros da equipe, a obediência às regras e comandos superiores, o reconhecimento dos próprios limites são algumas das armas mais poderosas para evitar os infortúnios. Uns afirmaram que o perigo e os acidentes não existem; outros já se deram conta de que não têm tanta autonomia para analisar e decidir sobre a realização do trabalho em situação perigosa.

Apesar do medo do desemprego, nem todos estavam plenamente satisfeitos com as atuais circunstâncias que envolvem o trabalho neste setor. Foi possível perceber vários tipos de reações quando o assunto é a privatização e a reestruturação: a apreensão quanto ao desfecho dos leilões das usinas hidroelétricas, o medo da revenda das empresas distribuidoras e das anunciadas falências das corporações que assumiram o controle das empresas. Para alguns a privatização era inexorável e a cada dia aumentava a frustração, o sentimento amargo de ter investido num projeto de trabalho e de vida e de ser impotente para impedir que tudo se acabasse em nada; para outros as incertezas incomodavam porque não era possível fazer planos para o futuro, que se apresentava obscuro porque no país há um desemprego crescente e generalizado. 
É que esses trabalhadores possuem uma especialização profissional muito bem definida, estão numa faixa etária próxima ou acima de 40 anos e, ainda, as suas condições de saúde já estão longe de ser as melhores. Muitos estão vivendo experiências de desemprego e privação através dos familiares, vizinhos, amigos e companheiros de trabalho que enfartaram, que adoeceram com as ameaças de desestabilização e o com clima competitivo e instável existente pré e pós-privatização. O depoimento de um técnico de manutenção é ilustrativo do significado negativo do clima organizacional individualista e competitivo existente:

As pessoas hoje estão preocupadas em querer saber aquilo que o outro faz mas, não querem ensinar para o outro o que ele faz. Eu vejo essa preocupação. Porque tem algumas pessoas novas e eles precisam da experiência, do conhecimento dos velhos porque o que vai garantir isso aí é essa transferência de conhecimento. Agora se os velhos começam a reter essas informações, os novos não vão saber [...] Isso é fruto dessa expectativa, desse momento que nós estamos passando.

Finalmente, este estudo, além de ter contribuído para melhor compreender a precarização das relações e condições de trabalho dos eletricitários, decorrentes das mudanças recentes implantadas no setor no contexto da privatização, apontou algumas direções para o aprofundamento desta problemática, abordando os seguintes aspectos:

- análise das relações e condições de realização do trabalho dos que são contratados pelas empreiteiras. Os trabalhadores diretamente contratados reconheciam que a situação dos indiretamente contratados era muito pior e que, em termos organizativos, esta é uma questão muito importante porque, quanto mais precária é a situação dos trabalhadores das empreiteiras, mais fraco se torna o poder de negociação da categoria;

- a medição das cargas de trabalho existentes nos ambientes de trabalho e a avaliação ergonômica das ferramentas e dos equipamentos de proteção individual (principalmente as luvas e os mangotes, os alicates e ferramentas pesadas);

- estudos específicos sobre os dois tipos de carga de trabalho mais significativas neste momento: as fisiológicas e as psíquicas;

- estudo da política de recursos humanos, especialmente a questão de treinamento e desenvolvimento organizacional no contexto da busca dos certificados de qualidade;

- estudo das condições de reprodução dos trabalhadores e suas famílias, envolvendo aspectos relacionados à moradia, acesso aos bens e equipamentos de consumo coletivo, principalmente nas áreas da saúde, educação, lazer.

Dada a complexidade da organização do setor, a velocidade com que ele vem se transformando e a sua importância social, a avaliação dos impactos da privatização e reestruturação empresarial para os trabalhadores deve tornar-se um processo rotineiro dentro do sindicato. Isso é fundamental para subsidiar o desenvolvimento de uma política sindical de saúde e segurança que contemple a assistência à saúde, a análise dos processos de trabalho e a vigilância ambiental em saúde, a orientação trabalhista e a formação política dos trabalhadores. Porque, neste momento, mais do que em qualquer outro, com ou sem "apagão", esta é uma questão de saúde e de segurança que não envolve somente esses trabalhadores, mas também toda a sociedade, dada a posição importante e estratégica que ainda assume o setor na matriz energética nacional. 
Privatisation, restructuring and changes in the working conditions: the case of the electric energy sector.

The restructuring and privatisation of the electric energy sector in the state of São Paulo Brazil has led to negative social consequences for the workers. Through data collected in interviews and direct observation, changes introduced in the technical base, in the division and organisation of the work were identified and also their effects for the worker's health and safety. In the generating power plants, the issues identified as the main factors leading to health problems were: noise, the night shift and the matter of working in shifts, the use of chemical products for the repair and maintenance of equipment. In the companies that deliver eletric power to the consumers, the problems identified were the night shift and the working in shifts and the performance of repetitive movements and physical efforts, wich lead to an increase in lesions. In both types of companies, and in the different work processes, the work load of a psychological nature is also very apparent, due to the intensification in the rhythm of the activities, by the awareness of an increase in insalubrious jobs, risk of injury and punishment at work, and by the atmosphere of instability which privatisation leads to.

Keywords: work organization, privatisation, health and safety at work.

Endereço para contato com a autora: scopinho@power.ufscar.br

Manuscrito recebido em: 26/03/2003

Envio de pareceres à autora em: 07/05/2003

Aprovado para publicação em: 20/08/2003

\section{Referências bibliográficas}

Antunes, R. (1995). Adeus ao trabalho? Ensaio sobre as metamorfoses e a centralidade do mundo do trabalho ( $2^{2}$ ed.). São Paulo: Cortez, Campinas: Editora da Unicamp.

Barbosa, E. R. (2000). O impacto da privatização na vida de um eletricitário: um estudo de caso. Dissertação de Mestrado em Serviço Social, Universidade Estadual Paulista Júlio de Mesquita Filho, Franca.

Benjamin, C. (2001). Foi loucura, mas houve método nela: gênese, dinâmica e sentido da crise energética brasileira. Caros Amigos, 51, 10-13.

Bernini, E. J. (1992). Reestruturação do setor elétrico paulista. Revista de Administração, 3, 16-28.

Banco Nacional de Desenvolvimento Econômico e Social (s. d.). Histórico do programa de privatização. Artigo disponível na Internet: http://www.bndes.gov.br/history.htm [13 novembro 1998]

Biondi, A. (1999). O Brasil privatizado: um balanço do desmonte do Estado. São Paulo: Fundação Perseu Abramo.

Dejours, C., Abdoucheli, E. \& Jayet, C. (1994). Psicodinâmica do trabalho: contribuições da escola dejouriana à análise da relação prazer, sofrimento e trabalho. São Paulo: Editora Atlas.

Fischer, T., Teixeira, E. \& Heber, F. (1998). Estratégias de gestão e reconfiguração organizacional: os setores de energia elétrica e telecomunicações. Revista de Administração Pública, 3, 9-27.

Folha de São Paulo (1999, 20 de agosto). Caderno Especial 1 Pós Privatização.

Folha de São Paulo (2001a, 19 de maio). Caderno Especial Guia do Racionamento. 
Folha de São Paulo (2001b, 20 de maio). Caderno Especial Crise de Energia.

Laurell, A. C. \& Noriega, M. (1989). Processo de produção e saúde: trabalho e desgaste operário. São Paulo: Hucitec.

Minayo, M. C. de S. (1999). O desafio do conhecimento: pesquisa qualitativa em saúde (6⿳亠丷厂 ed.) São Paulo: Hucitec, Rio de Janeiro: Abrasco.

Pereira, L. C. B. (s. d.). A reforma do Estado nos anos 90: lógica e mecanismos de controle. Artigo disponível na Internet: http:// www.clad.org.ve [20 junho 1999]

Sato, L. (1993). A representação social do trabalho penoso. In M. J. P. Spink (Org.), O conhecimento no cotidiano: as representações sociais na perspectiva da psicologia social (pp. 188-211). São Paulo: Brasiliense.

Teixeira, F. J. S. \& Oliveira, M. A. (1998). Neoliberalismo e reestruturação produtiva: as novas determinações do mundo do trabalho. São Paulo: Cortez, Fortaleza: Editora da Universidade Federal do Ceará.

Thiollent, M. (1997). Pesquisa-ação nas organizações. São Paulo: Atlas.

Túmolo, P. S. (1997). Metamorfoses no mundo do trabalho: revisão de algumas linhas de análise. Educação $\mathcal{E}$ Sociedade, 18 (59), 331-346.

Túmolo, P. S. (2001). Reestruturação produtiva no Brasil: um balanço crítico introdutório da produção bibliográfica. Educação \& Sociedade, 22 (77), 71-99. 